\title{
MOBILIDADE DO TRABALHO E TERRITORIALIZAÇÃO DO CAPITAL EM CRISE: APONTAMENTOS SOBRE O SENTIDO ATUAL DA SUPEREXPLORAÇÃO DA FORÇA DE TRABALHO
}

\author{
Ana Carolina Gonçalves Leite* \\ Universidade Federal do Espírito Santo
}

\author{
Daniel Manzione Giavarotti** \\ Universidade de São Paulo
}

\author{
Clara Lemme Ribeiro*** \\ Universidade de São Paulo
}

\begin{abstract}
Resumo: A partir da investigação de três processos distintos, significativos no contexto da formação territorial brasileira: a formação do "bóia-fria" e a migração temporária na modernização do campo; as migrações internas e a urbanização por expansão de periferias na metropolização de São Paulo e, por fim, as migrações internacionais de bolivianos na sua incorporação como trabalhadores em confecções na capital paulista o artigo busca discutir as relações entre superexploração da força de trabalho, migração e formação territorial tomando por base os conceitos de mobilidade do trabalho e territorialização do capital. Os paralelos estabelecidos entre esses três processos particulares permitem um debate com suas interpretações consagradas, doravante repensadas a partir da análise das transformações contemporâneas na mobilidade do trabalho e na territorialização do capital, à luz de uma reinterpretação da obra marxiana, apontando para a relevância do debate sobre o nexo entre estes últimos conceitos para a geografia crítica atual.
\end{abstract}

Palavras-chave: superexploração da força de trabalho; migração; formação territorial; mobilidade do trabalho; territorialização do capital.

\section{MOBILITY OF LABOR AND TERRITORIALIZATION OF CAPITAL IN CRISIS: NOTES ON THE SENSE OF CURRENT WORKING FORCE EXPLOITATION}

Abstract: Havig as a point of departure the investigation of three different and meaningful processes in the context of the brazilian territorial formation: the formation of the so called "bóia-fria" and the temporary migration entailed by the modernization of the relations of production in the countryside; the São Paulo's urbanization and metropolization through the expansion of the outskirts; and the bolivians' international migrations as well as their incorporation as workers in sewing workshops in this same city, this article aims to debate the relations between the overexploitation of the working force, migration and territorial formation based on the concepts of mobility of labor and territorialization of capital. The relations set among those three particular processes allow us to debate and criticize its acknowledged interpretations which could be rethought rooted on the analyses of the contemporary transformations over the mobility of labor as well as the territorialization of capital, in light of a reinterpretation of the Marxian work, pointing out the relevance of the debate on the ties between the first and the latter to the contemporary critical geography. Keywords: overexploitation of the working force; migration; territorial formation; mobility of labor; territorialization of capital.

\section{MOVILIDAD DEL TRABAJO Y TERRITORIALIZACIÓN DEL CAPITAL EN CRISIS: NOTAS SOBRE EL SENTIDO DE LA ACTUAL SUPEREXPLORACIÓN DE LA FUERZA LABORAL}

Resumen: Partiendo de la investigación de tres procesos distintos, significativos en el contexto de la formación territorial brasileña: la formación del "bóia-fria" (trabajador rural del corte de caña de azúcar) y la migración temporaria en la modernización del campo; la migración interna y la urbanización por expansión de las periferias en la metropolización de São Paulo; y las migraciones internacionales de bolivianos en su incorporación como trabajadores en talleres de costura en la ciudad de São Paulo, el artículo pretende discutir las relaciones entre superexplotación de la fuerza del trabajo, migración y formación territorial, basándonos en los conceptos de movilidad del trabajo y territorialización del capital. Los paralelos establecidos entre estos tres procesos particulares permiten un debate con sus interpretaciones consagradas que se pueden repensar especialmente a partir de un análisis de las transformaciones contemporáneas en la movilidad del trabajo y en la territorialización del capital, a la luz de una reinterpretación de la obra marxiana, señalando la relevancia del debate acerca de estos dos últimos conceptos para la geografía critica actual. Palabras-clave: superexplotación de la fuerza del trabajo; migración; formación territorial; movilidad del trabajo; territorialización del capital.

*Doutora em Geografia. Docente do Magistério Superior no Departamento de Ciências Geográficas da Universidade Federal de Pernambuco e Professora Colaboradora no Programa de Pós-graduação da Universidade Federal do Espírito Santo. Endereço: Av. Prof. Moraes Rego, 1235. Cidade Universitária, Recife (PE). CEP: 50670-901. ORCID: https://orcid.org/0000-0003-3121-4880. E-mail: carolinavecchia@gmail.com

** Doutor em Geografia. Desenvolve pesquisa de Pós-doutorado no programa de pós-graduação em Fllosofia da Universidade de São Paulo. Endereço: Rua Iquiririm, 663 -

São Paulo/SP - CEP: 05586-001 ORCID:https://orcid.org/0000-0003-0941-6179. E-mail: manzione79@usp.br

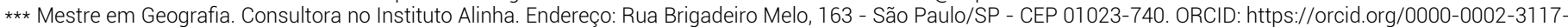
5706. E-mail: claralemme@gmail.com 
Introdução

0 presente artigo busca discutir a relação entre migração e formação territorial brasileira, a partir dos conceitos - e do nexo entre eles - de mobilidade do trabalho e territorialização do capital', numa leitura integrada de processos cujas interpretações pela teoria social brasileira tornaram-se clássicas: a formação do "bóia-fria" e a migração temporária na modernização do campo; as migrações internas e a urbanização por expansão de periferias na metropolização de São Paulo; e as migrações internacionais de bolivianos na sua incorporação como trabalhadores em confecções na capital paulista. Para além de traçar paralelos com as referidas análises consagradas, buscaremos observar os limites das mesmas ante as transformações contemporâneas na mobilidade do trabalho e na territorialização do capital, discutidas por cada um dos pesquisadores responsáveis pelo presente artigo à luz de uma reinterpretação da obra marxiana. Primeiramente apresentaremos os processos particulares elencados e as interpretações críticas que se consagraram, para num segundo momento apresentar as transformações históricas verificadas em cada um destes objetos, tendo como base as pesquisas levadas a cabo por cada um dos autores deste artigo. Tendo como parâmetro as transformações empíricas observadas em

'O processo de territorialização do capital impõe, por meio da (re)produção de determinada realidade sócio-espacial, de maneira ampliada e contraditória, a mobilidade do trabalho (Gaudemar, 1977). Ou seja, impõe a liberdade do trabalhador de ter de se sujeitar ao capital, como condição da reprodução do capital, em circunstâncias determinadas pelas particularidades e necessidades do processo de modernização (Kurz, 1999), entendido como a generalização de relações sociais de produção que têm na mercadoria sua forma central de mediação. Tal noção tem sua definição relacionada ao conceito de território, e mais precisamente, ao debate sobre qual o sujeito num processo de configuração territorial. O tratamento clássico conferido ao debate, pela Geografia Política, figura o Estado, especificamente o Estado nacional, como o agente responsável pela organização do território, como é possível reconhecer nos escritos de Ratzel e Vidal de la Blache (Damiani, 2002). Além deste, diferentes perspectivas na Geografia reconhecem também outros instrumentos de configuração do território como organizações e instituições, "do que adveio uma interpretação que supunha as relações de poder determinando o território e não exclusivamente o Estado" (Damiani, 2002: 17). Perspectiva política de interpretação da configuração territorial, que assume um caráter específico na Geografia de orientação marxista, em razão da determinação da dinâmica das relações de poder pela luta de classes: "O território é assim produto concreto da luta de classes travada pela sociedade no processo de produção da sua existência. (...) Dessa forma, são as relações sociais de produção e o processo contínuo/contraditório de desenvolvimento das forças produtivas que dão a configuração histórica específica ao território" (Oliveira, 1999: 74). Dinâmica própria, sobre a qual o Estado possui uma função regulatória: "(...) o território deve ser apreendido como síntese contraditória, como totalidade concreta do processo/modo de produção/distribuição/circulação/ consumo e suas articulações e mediações supraestruturais (políticas, ideológicas, simbólicas, etc.) em que o Estado desempenha função de regulação" (Oliveira, 1999: 74). Segundo Oliveira (1999), essa perspectiva sobre a configuração territorial tem sua formulação associada ao debate teórico promovido por autores como Lefebvre, Raffestin, Gottdiner, Coraggio, Quaini, Chesnais e Lacoste, entre outros. Ainda que a Geografia marxista tradicional apóie a determinação dos sujeitos das relações de poder que configuram o território na luta de classes, consideramos a possibilidade de interpretar a territorialização como um processo cujos sujeitos personificam o sentido do processo de modernização, cujo sujeito é o capital enquanto "sujeito automático" (Marx) da sociedade. Ou seja, a sociedade que territorializa é ela própria objeto da acumulação do capital. De acordo com essa interpretação, o capital torna-se aqui o sujeito de um processo que promove constantes rearranjos das relações territoriais para possibilitar a subordinação do trabalho e o movimento pelo qual ele acopla mais-valia, transformando sua própria grandeza, num movimento de autovalorização. Daí deriva a presente formulação sobre a territorialização do capital. cada um dos objetos analisados discutiremos a inadequação das interpretações consagradas para dar conta de tais transformações, apresentando uma relação entre o exercício da mobilidade do trabalho e a territorialização do capital que, diante dos desdobramentos contraditórios da reprodução do capital e sua crise imanente, desbancou o lugar ocupado pela superexploração da força do trabalho como esteio da modernização nacional.

Dentre as muitas discussões desdobradas da conceituação marxiana da força de trabalho, uma importante tradição que se estabeleceu na relação com os estudos migratórios foi a de crítica da mobilidade do trabalho e da acumulação do capital (GAUDEMAR, 1977). De maneira sintética, podemos retomar a problematização do referido autor sobre a mobilidade do trabalho como uma característica adquirida pela força de trabalho em sua formação. Essa característica estaria fundamentada na dupla liberdade do trabalhador que, no próprio processo que estabelece a moderna juridificação da sociedade capitalista, se torna, por um lado, sujeito livre para ir e vir internamente ao território e para fazer contratos e, por outro, livre de quaisquer condições de reprodução, meios de produção e mercadorias que não sua força de trabalho para realizar no mercado e, mediante a obtenção de salário, sobreviver.

Essa leitura expandiria o olhar sobre as migrações para muito além da ideia de um deslocamento passível de ser descrito como resultante, ora de um ato de vontade, ora de dinâmicas histórico-estruturais a organizarem contextos de repulsão e atração de migrantes, que poderiam ser supostamente apreendidos de maneira estatística. Encontraria as migrações como momento de um processo em que a mobilidade do trabalho é adquirida, no qual os corpos dos trabalhadores são produzidos para o trabalho, todavia sem nunca estarem terminados, incluindo assim uma inerente plasticidade que permite que sejam sempre remoldados durante seu consumo no processo produtivo, de modo a majorar as condições de extração da mais-valia - principal resultado desse último - seja ela relativa ou absoluta (cf. MARX, 1985a). As migrações se inseririam, portanto, num exercício da mobilidade que compreende constantes mudanças de função e jornada, readequação ao desenvolvimento técnico e possibilidade de demitir um trabalhador a qualquer momento.

Outro aspecto decisivo dessa abordagem corresponde à sua crítica a uma projeção espacial neutra segundo a qual os deslocamentos poderiam ser representados com recurso a pontos que se movem num plano cartesiano. Diferentemente, aqui, a mobilidade em seu exercício produziria tanto o espaço e o território (RAFFESTIN, 1993) como o corpo (HARVEY, 2006) para futuras mobilizações. A recepção brasileira da referida leitura 
veio conferindo bastante importância a esse aspecto, discutido pioneiramente nos trabalhos de VAINER (1984) e PÓVOA NETO (1998) e posteriormente investigado em inúmeras dissertações e teses, tais como ALVES $(2000,2007)$, TOLEDO $(2001,2008)$, BOECHAT (2009, 2014), KLUCK $(2011,2017)$ e SILVA $(2013,2018)$, além dos autores do presente trabalho, LEITE (2010, 2015), GIAVAROTTI $(2012,2018)$ e RIBEIRO (2018) ${ }^{2}$.

A forma de discutir esse problema não apenas teria contornos particulares em cada escala de análise, mas ela própria implicaria no desdobramento de diferentes escalas articuladas pelo processo compreendido como territorialização do capital. Da colonização responsável por inaugurar um sistema mundo desde então conformado por metrópole e colônia - as formas primevas da relação contraditória entre centro e periferia nos termos convencionados pela crítica do imperialismo (LENIN, 2010; LUXEMBURGO, 1985) - à constituição e crise dos Estados nacionais, a mobilidade do trabalho e a territorialização do capital recriariam condições de acumulação nos mais diversos contextos produzidos pela chamada expansão do capital.

\section{A força de trabalho superexplorada na modernização brasileira}

\section{Os "bóias-frias" entre a acumulação e a miséria}

Características próprias da produção agrícola teriam estabelecido os fundamentos de uma diferenciação entre cidade e campo, a qual Marx (1985b) se perguntava se resistiria ao progressivo desenvolvimento das forças produtivas, com a industrialização se estabelecendo à montante, à jusante e na própria agricultura, além de determinar a produção da própria terra e, com ela, da sua renda. Devido a essas características, o trabalho envolvido na sua reprodução, em cada uma das atividades concretas do plantio à colheita, é quase todo de dispêndio intermitente. Não seria, todavia, em função de nenhuma característica inerente à agricultura que as relações de produção que acompanharam o processo controversamente intitulado de "modernização da agricultura" no Brasil ganhariam a forma que ganharam. Para os estudiosos do problema, a emergência do trabalhador temporário apelidado "bóia-fria" fora determinada, antes, pelo fato de sua mobilização para o trabalho nunca ter sido acompanhada pelo efetivo reconhecimento do mesmo enquanto trabalhador, precisamente o que faria com que julgassem ser necessário agregar, para a caracteriza-

${ }^{2}$ As teses e dissertações mencionadas foram produzidas por pesquisadores do Laboratório de Geografia Urbana (LABUR), da Universidade de São Paulo. ção daquele processo de modernização, adjetivos como conservadora, dolorosa ou trágica (cf., por exemplo, MARTINS, 1981; MORAES SILVA, 1988, 1999; GRAZIANO DA SILVA, 1982; KAGEYAMA, 1990; THOMAZ JR., 2002).

Em poucas palavras, na mesma citada bibliografia, o "bóia-fria" aparece como o migrante que se assalaria sazonalmente nas empresas da agricultura capitalista em expansão. Do ponto de vista das suas relações no local de origem, é trabalhador temporário porque em geral tem acesso à terra na qual pode produzir gêneros alimentares, mas não em extensão suficiente para garantir a reprodução familiar, bastante transformada no processo que se seguiria à crise de uma dinâmica pregressa de caráter oligárquico, coronelista e regional. Assim, ele migra para complementar monetariamente sua subsistência e por isso se assalaria apenas uma parte do ano. Para o planejamento regional, que amiúde o interpretou como proveniente de "zonas de expulsão", o mesmo migraria para escapar da pobreza e da total falta local de oportunidade para o assalariamento. Do ponto de vista das suas relações no local de destino, ele é trabalhador temporário por conseguir se inserir unicamente em relações contratuais instáveis e muitas vezes não reconhecidas juridicamente.

Nas lavouras canavieiras integradas ou não em usinas voltadas para a produção de etanol combustível e açúcar branco refinado, o fato de boa parte daqueles trabalhadores serem migrantes e dos mesmos se imiscuírem em relações contratuais instáveis seria articulado mediante o papel exercido pelo arregimentador de trabaIhadores. Esse, que poderia ser ou não um empregado da usina, é conhecido como "gato", pessoa física responsável por terceirizar contratos, muitas vezes inclusive estritamente orais, intermediando trabalhador e empresa de maneira com que esses não travassem vínculo empregatício; ou a "gatona", pessoa jurídica com semelhante atribuição que ofereceria para a usina a colheita da cana como um serviço. Além de dissimular as relações de trabalho, ao arregimentador cabia também sustentar falsas promessas de fácil prosperidade e melhoria nas condições de vida, além de fazer uma espécie de adiantamento dos recursos monetários necessários para a passagem e a estadia até o recebimento do primeiro salário que resultava quase sempre em endividamento, base inclusive de relações possivelmente compulsórias de trabalho acrescidas às vezes até mesmo pela retenção de documentos (ALVES, 2008; MORAES SILVA, 1999).

Dentre os muitos aspectos agrupados na caracterização do "bóia-fria", o mais importante, sem dúvida, seria sua forma de remuneração, o salário por produção ou por peça, conforme conceituado por Marx (1985b). Para aumentar a produtividade dos "bóias-frias" essa 
aparecia como a mais adequada forma de pagamento por incitá-los a colher cada vez mais já que receberiam de acordo exatamente com tal quantidade. Além disso, teria o trabalhador ainda que fiscalizar a qualidade do seu produto, pois é paga a cana cortada dentro dos padrões da usina. Finalmente, somar-se-ia a esses recursos de intensificação do trabalho o chamado "pulo do gato", a conversão do preço por peça apenas estimado antes da realização do trabalho estabelecido por metro (metro linear nas cinco, seis ou sete ruas de cana paralelamente plantadas, a depender dos termos estabelecidos contratualmente) em preço efetivamente remunerado, o qual se define a posteriori, inclusive a partir da medição do índice de concentração da sacarose na cana colhida, remunerado por tonelada, ou seja, peso.

Tais condições de trabalho historicamente teriam produzido, como a bibliografia apontada não deixou de destacar, sistemáticos processos de adoecimento, incluindo problemas crônicos na coluna e articulações, câimbras, desidratações e desmaios durante o trabalho e até casos recorrentes de morte por excesso de trabalho (RAMOS, 2007; REDE SOCIAL DE JUSTIÇA E DIREITOS HUMANOS, 2009).

Enquanto forma da mobilidade do trabalho que teria sustentado a expansão da agricultura capitalista no Brasil, o "bóia-fria" foi sempre pensado como uma força de trabalho superexplorada na medida em que a extração da mais-valia nunca se restringiu à forma relativa, dependendo sistematicamente da absoluta. A ânsia de denúncia dessas condições fez com que a crítica levada adiante pela teoria social brasileira acabasse limitada aos termos excepcionais, em seus elementos contratuais ou internos, à intensificação do trabalho no processo de produção, da extração da mais-valia, não chegando, por vezes, nem a alcançar a própria exploração do trabalho assalariado enquanto tal (para uma crítica dessa perspectiva cf. LEITE, 2015).

Para os citados autores, o quadro no qual se teria estabelecido a superexploração da força de trabaIho como o mecanismo estruturante da expansão da agricultura capitalista no campo brasileiro incluiria o rebaixamento dos salários viabilizado pelo fato da reprodução das famílias não depender só da relação assalariada em que estavam engajados aqueles migrantes simultaneamente camponeses (aqui interessa distinguir que a ausência mesmo temporária dos migrantes exigia reestruturação do trabalho nas unidades familiares, impondo engajamento prematuro das crianças no trabalho e sobrecarga para o componente adulto não migrante, em geral mulher); a manutenção das extensões latifundiárias e a necessidade de remunerar o chamado "rentismo" característico da estruturação das classes sociais no país; o posicionamento associado da burguesia nacional ao capital monopolista imperialista que assentou níveis elevadíssimos de acumulação antes na intensificação do trabalho que no desenvolvimento das forças produtivas; e, por fim, os francos limites no estabelecimento de direitos civis e trabalhistas para as classes populares, definidos nos termos da ditadura civil-militar que organizara a referida modernização.

\section{A superexploração e a autoconstrução na formação da classe trabalhadora urbana em São Paulo}

O problema que a mencionada falta de identidade entre a intermitência característica das atividades agrícolas e a forma particular em que se deu a incorporação de trabalhadores "bóias-frias" levanta fica evidente também quando tomamos o processo de industrialização ocorrido em São Paulo, pelo menos a partir de 1950. Inclusive porque a mobilidade do trabalho experimentada pela massa de migrantes nacionais que se encaminharam para São Paulo, não obstante seu caráter não intermitente, apresentou o mesmo tipo de questão apontada pelos autores que se dedicaram a estudar o trabalho dos "bóias-frias": a superexploração das forças de trabalho, mas neste caso, empregadas pelos capitais urbano-industriais.

Oliveira (2003) e Marini (2005) buscaram, cada um a seu modo, compreender as raízes da superexploração da força de trabalho urbana como fundamento da formação do capitalismo periférico, igualmente pelo viés da crítica ao imperialismo. 0 primeiro seria pioneiro, todavia, em inscrever no debate acadêmico o estabelecimento de uma forma particular de mobilidade do trabalho própria à "industrialização tardia" (OLIVEIRA, 2003: p. 67) a partir do reconhecimento da autoconstrução ter se tornado a forma hegemônica de acesso à moradia por parte da classe trabalhadora urbana. Para Oliveira (2003), a autoconstrução - produção de habitação feita pelas próprias famílias trabalhadoras em regimes de "mutirão" expressava, simultaneamente, um regime de exploração baseado na mais-valia absoluta, já que o tempo de trabaIho necessário à reprodução do trabalhador estendia-se para além da jornada de trabalho diária e a própria superexploração da força de trabalho em âmbito produtivo, já que a necessidade de aquiescerem à autoconstrução indicava que os trabalhadores não estariam recebendo o salário correspondente aos custos de reprodução de 
suas forças de trabalho ${ }^{3}$. Segundo o autor, portanto, a superexploração da força de trabalho, reforçada pela prática da autoconstrução guardaria funcionalidade à acumulação do capital industrial uma vez que o rebaixamento dos custos de reprodução do trabalho permitiria maiores taxas de mais-valia. Tal excedente seria dividido entre uma quota remetida às economias centrais, dada a enorme participação do capital estrangeiro na industrialização brasileira (cf. MARINI, 2005) e outra permaneceria em território nacional, ainda que a segunda não fosse suficiente para dar impulso a uma efetiva industrialização em bases nacionais. Portanto, a superexploração da força de trabalho e não o aumento da produtividade média do trabalho, permaneceria organizando os termos da modernização brasileira, assim como a continuidade de investimentos do capital estrangeiro.

Kowarick (1993), partindo da interpretação de Oliveira (2003), retomará o problema, mas observando-o à luz da sociologia urbana, integrando na análise elementos referentes às condições infraestruturais dos loteamentos periféricos constituídos pela população trabalhadora urbana onde a ausência do Estado, em sua suposta função de provedor do direito à habitação assim como das infraestruturas urbanas necessárias à reprodução social capitalista, ganha centralidade de maneira distinta que na argumentação de Oliveira (2003). 0 autor amplia o escopo da problemática, associando ao problema da superexploração da força de trabalho aquele da ausência das condições mínimas de reprodução, cunhando a noção de "espoliação urbana" como o "somatório das extorsões" (cf. KOWARICK, 1993) às quais a classe trabalhadora urbana estaria submetida. Enquanto para Oliveira (2003) o problema da autoconstrução deveria ser remetido à distribuição extremamente desigual entre capital e trabalho, o último, sem desconsiderar esta problemática e inclusive sublinhando o papel desempenhado pelo exército industrial de reserva no rebaixamento dos salários, buscava apontar para uma problemática que se sobreporia à última, aquela referida ao papel do Estado no planejamento do espaço urbano e aprovisionamento de infraestrutura e habitação social. Em outras palavras, Kowarick (1993) reivindicava que os trabalhadores fossem observados

${ }^{3}$ Em palestra de 2006, no qual o autor revisita essa mesma problemática, ele será explícito ao afirmar que os custos relativos à habitação teriam sido suprimidos da cesta de consumo do trabalhador a partir da "revolução burguesa" (cf. OLIVEIRA, 2003) e a instituição do salário mínimo. Em resposta ao espanto que essa descoberta possa provocar, sugerindo a prática típica de uma modernização conservadora, vale a observação de Marx sobre a acumulação primitiva: "Para o curso usual das coisas, o trabalhador pode ser confiado às 'leis naturais da produção', isto é, à sua dependência do capital que se origina das próprias condições de produção, e por elas é garantida e perpetuada. Outro era o caso durante a gênese histórica da produção capitalista. A burguesia nascente precisa e emprega a força do Estado para 'regular' o salário, isto é, para comprimi-lo dentro dos limites convenientes à extração de mais-valia, para prolongar a jornada de trabalho e manter o próprio trabalhador num grau normal de dependência. Esse é um momento essencial da assim chamada acumulação primitiva" (Marx, 1985b: p. 277 - grifo nosso) como sujeitos de direito, ainda que sem direitos. Esta última interpretação nos interessa à medida que, para o autor, teria sido o fechamento imposto pela ditadura civil-militar à participação política da classe trabaIhadora, o responsável de que a mesma não pudesse disputar seus interesses de classe para buscar alterar os rumos das políticas econômicas em curso. Assim, não obstante os elementos estruturais da inserção do Brasil na divisão internacional mundial do trabalho, especialmente sublinhada por Marini (2005), a condição da classe trabalhadora parecia poder ser contornada por opções políticas relativamente autônomas, preferencialmente se levadas à cabo por aqueles sujeitos.

\section{Migrantes bolivianos na indústria de confecção}

Após o esgotamento da ditadura civil-militar brasileira, especialmente nos anos 1990, consolida-se um processo migratório internacional de bolivianos para a região metropolitana de São Paulo que se inserem como costureiros em pequenas oficinas de costura irregulares. A superexploração da força de trabalho que havia sido identificada nos migrantes internos sazonais e naqueles que formaram as periferias urbanas do sudeste aparecia, então, desdobrada nas relações de trabalho dos novos migrantes internacionais.

A pesquisa etnográfica pioneira de Sidney Silva (1997) inaugurou o campo de debate sobre a questão. As formas de trabalho das oficinas de costura foram compreendidas, a nível jurídico, como trabalho análogo ao de escravo. 0 debate centrou-se sobre explicações para tais condições de trabalho e para a submissão dos migrantes a elas. Em certas pesquisas, a migração da costura foi compreendida como parte de uma reestruturação produtiva na indústria de confecção no final dos anos 1990, em resposta a uma crise do setor, como apresentado na pesquisa de Carlos Freire da Silva (2008). Em crítica a essa perspectiva, Freitas $(2009,2014)$ considerou que a inserção de bolivianos nas oficinas se devia a fatores históricos estabelecidos a partir das reformas neoliberais na Bolívia nos anos 1980, que flexibilizaram e precarizaram o regime de emprego, elevando índices de desemprego e pobreza no país, em relação à migração de coreanos que se estabeleceram no mesmo setor criando as condições para a inserção dos migrantes bolivianos na costura (para uma crítica das duas perspectivas cf. RIBEIRO, 2018). Mais recentemente, Miranda (2017) interpretou o problema como uma sobreposição de aspectos consentidos e não consentidos de trabalho.

Neste contexto as oficinas estabelecem longas jornadas de trabalho que, em geral, duram de $7 \mathrm{~h}$ a $22 \mathrm{~h}$ de segunda a sexta, de $7 \mathrm{~h}$ a $13 \mathrm{~h}$ aos sábados, com descanso aos domingos. Esses horários podem variar de 
acordo com a demanda e os prazos de entrega das encomendas de costura. A oficina oferece, ainda, alimentação nos períodos de trabalho e moradia para os costureiros. 0 projeto migratório costuma ser formulado como temporário, como estratégia para "juntar um dinheiro" - para pagamento dos estudos universitários, compra de um imóvel, abertura de um negócio, quitação de uma dívida etc. - com um retorno próximo, após um ano ou dois, o que também justificaria a submissão às condições de trabalho da costura. Por outro lado, a indocumentação de grande parte dos migrantes explicaria ainda sua dificuldade ou mesmo impossibilidade de inserção no mercado laboral formalizado.

Em um primeiro momento, especialmente entre as décadas de 1980 e 1990, as oficinas eram de propriedade de coreanos que contratavam bolivianos como costureiros para alimentar suas próprias lojas e marcas. Aos poucos, houve uma transferência dessa propriedade dos primeiros para os segundos, enquanto os coreanos se estabeleciam na distribuição das roupas, com investimentos cada vez maiores na criação de lojas e marcas próprias (cf. FREITAS, 2009). Assim, os bolivianos tornaram-se donos das oficinas, especialmente em casais, e o uso dessa força de trabalho generalizou-se para a maior parte do setor.

Esse processo reconfigurou o agenciamento dos costureiros migrantes, que é feito já na Bolívia de diversas maneiras, seja por meio de anúncios que circulam em rádios, jornais e televisão, de atravessadores que vão à Bolívia "buscar" trabalhadores ou de familiares que "trazem" irmãos, pais, primos, cunhados, sobrinhos e vizinhos. Assim, os bolivianos chegam a São Paulo já sabendo onde vão trabalhar e cada oficina encontra seus próprios caminhos para recrutar costureiros através de níveis diferentes de relação pessoal ou impessoal. Mesmo no caso de familiares próximos, o agenciamento inclui também o pagamento da viagem de ida, o que cria para o migrante uma dívida inicial com o atravessador, o dono da oficina ou ambos. Ainda que possam migrar em qualquer período do ano, a maior demanda de trabalho acontece na alta temporada da costura, entre outubro e dezembro, havendo também uma migração apenas para o trabalho nesses meses. 0 migrante recém-chegado entra na oficina como aprendiz e ajudante, auxiliando em tarefas como dobrar e passar as roupas, fazer pequenos acabamentos, entre outras, enquanto aprende a costurar no resto do tempo. As mulheres podem ser integradas à oficina também como ajudantes ou como cozinheiras e faxineiras.

Assim como no corte da cana, a remuneração na costura é o salário por produção ou por peça. As oficinas podem receber o pedido de um intermediário que irá reven- der a roupa costurada em sua própria loja ou a terceiros, ou ainda negociar diretamente com o distribuidor final. Nesse pedido, já se fixa o preço por peça pago ao dono da oficina, que repassa uma parte ao costureiro dependendo do tipo de serviço e da máquina em que será executado, podendo variar mais ou menos de $\mathrm{R} \$ 0,10$ a $\mathrm{R} \$ 3,00$. Há uma grande variação na quantidade de peças que um costureiro executa por dia, dependendo do tipo de serviço a ser realizado e do tempo gasto em cada peça. Como consequência, impera uma concorrência interna às oficinas de disputa pelos melhores serviços e, ainda, uma pressão sobre a aceleração dos tempos de produção em nome do ganho e, também, da necessidade de terminar um pedido mais rápido para conseguir pegar o próximo serviço antes que o outro costureiro (cf. MIRANDA, 2017).

As oficinas apresentam condições de insalubridade como recintos fechados, com pouca ventilação e iluminação, inundados de poeira, que levam ao adoecimento dos trabalhadores de formas diversas, principalmente doenças respiratórias e tuberculose, além de lesões em mãos, braços e nas costas causadas pelos movimentos repetitivos nas máquinas (cf. GOLDBERG e SILVEIRA, 2013). Importante lembrar que tais casos de doença, bem como incêndios provocados pelas instalações elétricas precárias, levam muitas vezes à morte desses trabalhadores. As mulheres enfrentam ainda formas de violência sexual e doméstica.

Nas análises que consideram que tais formas de trabalho se formaram sob um processo de reestruturação produtiva da indústria de confecção apontam para a superexploração da força de trabalho do migrante como uma necessidade de rebaixamento de custos causada por um contexto global de concorrência e acumulação flexível que obrigaria à formação de empregos precarizados, ao qual apenas imigrantes vulneráveis e impedidos de se reproduzir nos seus próprios países aceitariam se sujeitar. Ademais, o padrão de consumo da moda exigiria uma rápida substituição das mercadorias disponíveis, obrigando uma produção de poucas peças em prazos exíguos que só poderia ser atendida pelas oficinas de costura (cf. MONTERO, 2014). Nessa perspectiva, o alargamento da extração da mais-valia absoluta pela extensão das jornadas de trabalho reporia a crise de acumulação do setor de confecção, que estaria limitada pela impossibilidade de uma inovação técnica das máquinas de costura que elevasse os níveis de mais-valia relativa. A submissão dos costureiros a essas jornadas estaria dada tanto por formas de engano e coerção quanto pela sua própria condição empobrecida na origem. 
Superexploração contemporânea: persistência e reposição do atraso ou crise da modernização?

\section{A superexploração mecanizada}

Os termos com que a teoria social brasileira desenharia a mobilidade do trabalho estabelecida no campo brasileiro com a expansão da agricultura capitalista, sistematizáveis na noção de superexploração, implicariam, como vimos, numa determinada forma de territorialização, conceituada com recurso à crítica do imperialismo. Nas diferentes escalas nas quais o processo iria se desdobrar, eles incluíram a perspectiva de que a expansão capitalista implicava na reprodução de relações não capitalistas de produção (definidas pelo acesso à terra e, com ela, à produção direta de meios de vida) a diferenciar e combinar origem e destino, internamente ao território nacional, tornando possíveis, nessa última, níveis de acumulação extraordinários, impostos a expensas da primeira. Como também incluíram a perspectiva de que o caráter associado em uma posição dependente da industrialização nacional, na qual o Departamento I, que produz as condições de reprodução da indústria, os chamados bens de produção, nunca chegaria a ser internalizado (OLIVEIRA e MAZZUCCHELI, 1977), refrearia o desenvolvimento das forças produtivas como mola da ampliação dos níveis de extração de mais-valia impondo constantemente a recriação de uma forma tomada como atrasada de mobilidade para sustentar a acumulação.

Olhado de hoje, inclusive a partir de transformações ocorridas na modernização da agricultura, entre elas, por exemplo, a ampla mecanização da colheita na lavoura canavieira em muitos estados brasileiros, aquele modo de interpretar o "bóia-fria" poderia ser bastante problematizado. Uma oposição importante, que questiona a perspectiva de que a superexploração da força de trabalho se relacionava com níveis de desenvolvimento técnico represados pelo imperialismo, permite reconhecermos que, apesar da mecanização, condições degradantes de trabalho se reproduzem até mesmo entre os operadores das máquinas colheitadeiras (cf. LEITE, 2014). E não dizemos isso buscando dissimular o trabalho manual que ainda se reproduz amplamente mesmo nas lavouras cuja colheita foi mecanizada, por exemplo, na figura dos "canudeiros", cortadores de cana que abrem manualmente o canavial para que entrem as colhedeiras, ou das "catadoras de pedras" que procuram limpar o terreno de empecilhos físicos de modo a preservar em bom funcionamento as máquinas, como sugerem estudiosos (MORAES SILVA e BUENO e VERÇOZA, 2013).

Diferentemente, nos perguntamos como pensar o fenômeno da superexploração da força de trabalho manual ou mecanizado em uma sociedade não apenas nacional em que o desemprego se expande ampliadamente e que os contextos de concorrência cada vez mais acirrada entre os trabalhadores obrigam-nos a aceitar condições mais e mais deterioradas mesmo quando a legislação trabalhista avançou em muitos daqueles aspectos que caracterizavam a precariedade contratual e a produção do trabalho do "bóia-fria". E não porque a mais-valia absoluta não possa ser mobilizada mais para apreender tais relações de trabalho, mas porque ela hoje é necessária de ser problematizada quando a participação do Estado mediante recursos do seu fundo público se tornou pressuposto da reprodução do capital (cf. OLIVEIRA, 1998) garantindo, por um lado, o processo de futurização da realização capitalista fundado em um endividamento já estrutural e, por outro, a reprodução dos trabalhadores, cada vez mais permeada por benefícios e programas estatais. Os referidos recursos do fundo público, por sua vez, incidem também, diretamente, na chamada reprodução camponesa, na origem, exigindo questionar a própria ideia de que a mesma efetivamente sustente o rebaixamento dos salários e esse, por sua vez, a acumulação.

\section{A periferia consolidada: \\ da reprodução à "produção"}

A consolidação dos loteamentos periféricos e favelas na conformação urbana da metrópole de São Paulo envolveu uma intensa modificação nas formas de uso do espaço e do tempo (cf. SEABRA, 2003) agenciados por esses moradores. A "propriedade" adquirida por meio da autoconstrução empreendida pelas famílias trabalhadoras no processo de constituição destas periferias veio historicamente adquirindo novos usos que poderiam ser colocados sob a alcunha de produtivos (cf. GIAVAROTTI, 2018). Em outras palavras, as moradias estabelecidas nesses territórios, sejam elas legais ou ilegais, formais ou informais, vem abrigando uma série de estratégias de reprodução que se confundem com atividades produtivas, na maioria das vezes entabuladas por filhos e/ou netos das primeiras famílias que deram origem a estes loteamentos e autoconstruíram suas moradias.

A emergência desta forma particular de mobilidade do trabalho pode ser atribuída ao fato de que, não obstante a superexploração experimentada pela classe trabalhadora num contexto de capitalismo dependente em seu processo de industrialização, as condições particulares da relação entre terra e trabalho naquele contexto criou a situação peculiar de uma coincidência entre ser trabalhador assalariado superexplorado e pequeno proprietário de terra, desdobrando-se criti- 
camente na emergência dessas práticas "produtivas" num território historicamente destinado à reprodução.

0 incremento destas atividades "produtivas" empreendidas pelas novas gerações de trabalhadores imiscuídas nestes territórios periféricos pode ser atribuído ao aprofundamento da dinâmica "populacional" acusada por Oliveira (2003) e Kowarick (1993) já na década de 1970. Ou seja, se o processo de constituição das próprias periferias de São Paulo e outras metrópoles brasileiras respondeu, ao menos em parte, pela existência de um exército industrial de reserva a forçar o rebaixamento dos salários em direção à reprodução atrofiada das forças de trabalho (superexploração), seria um desacerto abandonar uma pergunta sobre essa questão em particular na relação que continua a se estabelecer, por um lado com a reposição da superexploração e, por outro, com as transformações em curso verificadas nas periferias e no exercício da mobilidade do trabaIho destas populações periféricas. Em outras palavras, a lei populacional própria ao capital (cf. MARX, 1985b) não deixou de determinar a reprodução social desde as considerações de Kowarick (1993). No entanto seria enganoso acreditar que toda a população trabalhadora de São Paulo se tornara empresária de si mesma (cf. KURZ, 2006). Há uma boa parcela desses moradores de periferias que continua se assalariando, em regimes temporários de trabalho, terceirizados, precarizados, que poderiam ser também colocadas sob a alcunha de superexplorados, já que a ausência de direitos e o rebaixamento de seus salários permanece como traço importante. Entretanto o processo histórico parece revelar que aquilo que aparecia como secundário nas análises da teoria marxista da dependência, como o exército industrial de reserva, ganhou uma relevância nunca antes vista, ainda que chamar a superpopulação relativa (cf. MARX, 1986) contemporânea de exército industrial de reserva pareça já ser um anacronismo, como veremos.

\section{Crise na costura: novas formas de superexploração?}

O trabalho de migrantes bolivianos da indústria de confecção paulistana passou por diversos momentos: primeiro, ligado à comunidade coreana inserida no setor de vestuário; em seguida, já generalizado como força de trabalho de grande parte da indústria local; e, a partir de 2014 , segundo relatos dos próprios migrantes, a "crise da costura", em que houve uma queda nos preços pagos por cada peça e, mais que isso, na demanda do próprio setor, reduzindo ganhos de costureiros e donos de oficina. Com isso, observa-se o retorno de parte dos migrantes ou a saída da costura para outros empregos, quando possível.

Os termos dessa crise precisarão ainda ser decifrados. No entanto, já se veem algumas tendências entre aqueles que permanecem na costura. Uma das estratégias que surgem é "cortar o intermediário", isto é, o dono da oficina encontra formas de vender as suas peças diretamente ao cliente final, seja em pequenos boxes em galerias no Brás ou outros bairros de comércio popular, seja nas feiras da madrugada realizadas nesses mesmos bairros. Ao mesmo tempo, a baixa demanda de serviços leva os donos de oficina a reduzir o número de costureiros, cortando inclusive ajudantes, cozinheiras e faxineiras, tarefas que são acumuladas nos donos e costureiros, especialmente mulheres, no caso das atividades domésticas. Também se torna cada vez mais comum encontrar costureiros independentes, que trabalham para outras oficinas - mas utilizando uma máquina de costura pessoal, em sua própria casa - ou para lojas e firmas que fazem pedidos da mesma forma que o fazem com oficinas maiores. Mesmo estes costureiros buscam formas de vender as suas peças "cortando o intermediário", realizando individualmente todas as etapas entre a produção da peça e a sua venda final. 0 ritmo e a jornada de trabalho são, nesses casos, determinados pelo prazo e tamanho do serviço a ser entregue, mas podem ser acelerados para que o costureiro pegue novos trabalhos.

Carlos Freire da Silva (2008) considerava à época que, como medida efetiva para a erradicação da superexploração da força de trabalho de migrantes bolivianos na costura, a responsabilização sobre a irregularidade do trabalho deveria recair sobre as marcas para as quais a oficina clausurada pelo Ministério do Trabalho produzia as peças de roupa, e não sobre os donos também migrantes - como acontecia. Essa política foi efetivamente adotada posteriormente, porém sem garantir a erradicação esperada; ao contrário, mesmo com a medida, houve uma expansão do circuito das oficinas de costura que hoje se pulverizam inclusive como costureiros individuais, como comentamos, mantendo as longas jornadas e a alta produtividade. 0 que parece, no entanto, ter reduzido o trabalho de bolivianos na indústria de confecção paulistana foi a "nova" crise do setor, inaugurada em 2014, que diminuiu a demanda e assim as horas de trabalho, ocasionando mesmo o retorno.

A perspectiva da reestruturação produtiva indicava que esta reorganização da cadeia produtiva da costura teria resolvido a crise da indústria de confecção. No entanto, décadas depois, nos vemos diante de uma "nova" crise que recoloca o problema: a chamada superexploração da força de trabalho parece 
já não dar conta de garantir a redução de custos e a maximização dos lucros do setor. A superexploração da força de trabalho imigrante, isto é, a tentativa de elevação das taxas de mais-valia da indústria de confecção, parece não ter resolvido a crise do setor nos anos 1990 que hoje retorna como "crise da costura".

Além disso, há um deslocamento da figura do explorador, em que a marca e o dono da oficina, embora mantenham a sua centralidade, parecem agora concorrer com os próprios costureiros, que organizam e gerenciam individualmente a sua própria superexploração. Em outras palavras, esta aparece já autonomizada (cf. MARX, 1986) da pressão de donos e marcas e assumida subjetivamente pelos costureiros. Não se trata, então, de migrantes empobrecidos, enganados e submissos, mas de trabalhadores e empresários de si mesmos (cf. KURZ, 2003) que assumem os termos impostos pela concorrência generalizada do setor - entre os quais se encontram, inclusive universitários e profissionais liberais.

Assim, o contexto atual nos permite repensar o argumento da superexploração - que parece supor um nível de exploração aceitável, definido em termos jurídicos - e repensar também as condições em que o migrante se torna parte da cadeia "produtiva" da indústria da confecção.

\section{Conclusão}

A leitura paralela de problemáticas tão diversas como as expostas aqui sugere formas particulares de mobilidade do trabalho movidas por um mesmo processo, qual seja, a modernização das relações sociais de produção em distintas escalas. Foi possível identificar como se operam as transformações na mobilidade do trabalho, seja observando a migração temporária entre campo e cidade na modernização da agricultura, a migração definitiva campo-cidade que deu ensejo à urbanização por expansão de periferias articulada à industrialização, ambas circunscritas à escala nacional, ou ainda as novas migrações internacionais, intermitentes ou definitivas, que nos remetem à escala mundial. Faltaria, por fim, considerar os termos do processo de formação da mobilidade do trabalho no Brasil para delinearmos as diferenças presentes na suposta unidade relativa à "permanência" da superexploração da força de trabalho em cada um desses contextos, observando sua nova qualidade para além da tão conhecida modernização conservadora.

De acordo com Marx (1985b) o projeto de "colonização sistemática" teria sido desenvolvido como estratégia para criar trabalhadores assalariados nas colônias, estabelecendo o sufficient price que impediria o acesso dos colonos à terra, logrando assim a produção de uma superpopulação relativa. A colônia acabaria, assim, por revelar o segredo da metrópole: a expropriação dos trabaIhadores e a sua formação como força trabalho ou, ainda, o processo de mobilização para o trabalho. Se tal mobilização tomou a forma da acumulação primitiva e dos cercamentos na Inglaterra, a sua realização em outros contextos exige ser compreendida de forma particular, ou seja, a partir das suas próprias condições históricas. Pode-se dizer, ainda, que cada processo particular de mobilização para o trabalho é acompanhado de um padrão correlato de territorialização do capital (cf. LEITE, 2015).

Portanto, a pergunta sobre a formação da mobilidade no Brasil pede um estudo da formação nacional vinculada a padrões de territorialização do capital, entre os quais se pode identificar a substituição do trabalho escravo pelo trabalho livre. 0 debate foi polarizado por autores que interpretavam as primeiras formas do trabalho livre como por exemplo, o colonato, a morada ou a agregação, como um quase assalariamento com produção direta dos meios de vida, e autores que as compreendiam como formas quase camponesas com momentos mediados pela remuneração em dinheiro. Para alguns autores (cf., por exemplo, TOLEDO, 2001, 2008; BOECHAT, 2009, 2014; LEITE, 2010, 2015; KLUCK, 2011, 2017), essas eram as formas possíveis de mobilização do trabalho em um contexto que, ao mesmo tempo, garantia uma ampla disponibilidade de terras e impossibilitava a manutenção do trabalho cativo. Não havia, naquele momento, condições para a formação de uma superpopulação relativa porque a fronteira fundiária estava aberta e o nível de desenvolvimento técnico não assegurava, por si só, a expulsão relativa da força de trabalho da própria produção, o que se encontra com o acesso à terra e a produção direta dos meios de vida.

Assim, para criar condições para o processo de acumulação capitalista era necessário controlar o acesso à terra, o que foi imposto pelas grandes fazendas no curso de sua expansão. Com isso, não havia condições para a autonomização entre terra e trabaIho ou entre capital, terra e violência (cf. LEITE, 2015), relação que aparecia como coronelismo, domínio político e curral e que implicava em uma espécie de fechamento territorial. A mobilização para o trabalho ficava então circunscrita à forma identificada como regional (cf. OLIVEIRA, 1987), isto é, à forma territorial particular de reprodução do capital naquele contexto.

Aquelas condições que impuseram o escravismo e as relações regionais de produção foram, no entanto, profundamente modificadas. Linearmente, estas trans- 
formações podem ser compreendidas como expansão da renda fundiária, que consolidou decisivamente a propriedade privada no país; amplitude dos processos de expropriação e formação de um mercado de trabalho à escala nacional, evidenciados pelo chamado êxodo rural e generalização do assalariamento; institucionalização do Estado e da sua tecnocracia promotora do planejamento; internalização da metrópole e sua expressão como metropolização; industrialização e formação de um sistema ampliado de crédito; entre outros.

Nestas transformações podemos também localizar os diferentes momentos da mobilidade do trabalho no Brasil que discutimos neste artigo, das quais a migração sazonal para o corte de cana, a migração definitiva campo-cidade formando periferias metropolitanas e a migração internacional inserida em empregos informais e precários são exemplos. Cada um desses momentos corresponde ainda a processos de territorialização do capital que abarcaram a "modernização da agricultura" e a urbanização e a industrialização concentrada no estado de São Paulo, mobilizando migrantes internos e internacionais.

Tais processos, geralmente apreendidos como desenvolvimento, convergem para um horizonte de crise devido à dinâmica temporal própria do capitalismo (cf. POSTONE, 2014), do qual emergem as formas contemporâneas de confinamento anteriormente descritas, derivadas de uma reconfiguração da territorialização do capital. Assim, estas formas nem podem ser compreendidas como mera reprodução do atraso nem podem ser igualadas, a não ser no plano fenomênico, àquelas que as precederam. As chamadas formas de "trabalho escravo" do corte da cana, o trabalho autônomo de baixíssima capitalização em expansão nas periferias ou ainda a indústria da confecção, exigem ser repensadas para além de uma igualação ao trabalho escravo da colonização ou algo que o valha. Migrantes internos sazonais, microempreendedores periféricos ou migrantes bolivianos já estão, desde há muito, formados como trabalhadores portadores da sua liberdade contraditória (cf. GAUDEMAR, 1977). No caso dos costureiros, ainda, seu cotidiano confinado às oficinas parece já prescindir de uma imposição estrita dos donos das últimas ou de marcas de roupa. Também se assiste, hoje, a novas formas de confinamento da população periférica, seja na forma do encarceramento em massa, seja na formação de novas centralidades no espaço metropolitano, concentrando atividades "produtivas" e de consumo, reconfigurando as próprias periferias, já qualificadas como "campos de concentração a céu aberto" (cf. AUGUSTO, 2010).

Se é verdade que a superexploração da força de trabalho não deixou de estar presente na vida de milhões de trabalhadores, independente dos setores nos quais se encontram mobilizados, diante das formas contemporâ- neas de territorialização do capital tal categoria crítica tornou-se obsoleta como forma de definir e circunscrever a problemática à qual esta prática corresponde - as quais passam ao largo das soluções imaginadas, seja na forma de um aumento da produtividade do trabalho (passagem da mais-valia absoluta para mais-valia relativa), seja na forma da expansão dos direitos de cidadania. Vejamos essa afirmação do ponto de vista da lógica interna da própria reprodução ampliada do capital.

A concorrência entre os diferentes capitais exige o reinvestimento da mais-valia cada vez que o ciclo da produção mercantil se reinicia. A possibilidade de se extrair sobrelucro (cf. MARX, 1986) a partir do rebaixamento dos custos das mercadorias, provocado pela elevação da produtividade do trabalho, acaba por motivar o incremento das forças produtivas. Seguindo essa pista, o que aparece como desenvolvimento da reprodução ampliada, ou acumulação do capital, é a sua tendência ao aumento da razão entre capital constante (matérias-primas, instalações e, especialmente, maquinário) e capital variável (força de trabalho), a chamada composição orgânica do capital (cf. MARX, 1985b)4. Tal desenvolvimento aparece como ascendente mas comporta, em si, uma contradição que lhe é imanente: o aumento da composição orgânica do capital implica na expulsão sistemática do trabalho vivo da produção, ao mesmo tempo em que o fundamento único do processo de valorização do capital é justamente a mobilização do trabalho vivo. Nessa contradição Marx encontra o fundamento da crise do valor como a forma social da riqueza (cf. POSTONE, 2014), o qual aparece na forma de uma queda tendencial da taxa de lucro (MARX, 1988), a despeito da pressão exercida pelas chamadas "contratendências", estratégias que visariam compensá-la ${ }^{5}$. Tal processo é próprio da lógica da reprodução capitalista, por isso foi identificado por Marx já na segunda metade do século XIX (cf. LEITE, LEITE e GIAVAROTTI, 2018), ainda que tenha sofrido desdobramentos particulares ao longo da história da modernização capitalista, os quais, todavia, não arrestaram seu sentido. Apesar do caráter imanente dessa crise, houve momentos de resolução aparente, como a expansão territorial da relação-capital, a criação de novos setores de produção de mercadorias e a subsunção à lógica empresarial de atividades "não-tipicamente capitalistas" ou que correspondiam ao âmbito reprodutivo. Por isso, a generalização das indústrias automobilística, de eletrodomésticos,

${ }^{4}$ Em Marx (1983), o trabalho vivo foi compreendido como capital variável enquanto matérias-primas primas, instalações e maquinário foram pensados como capital constante. Somente o capital variável seria, assim, capaz de criar um valor, um valor novo maior do que aquele pago como salário para a entrada do trabalho no ciclo produtivo - daí o seu caráter variável.

${ }^{5} E$ neste particular que a releitura da obra de Karl Marx feita por Moishe Postone (2014) e Robert Kurz (1993) se diferenciam daquelas leituras que compreendem de forma cíclica as crises do capitalismo (cf. HARVEY, 2011; 2013) 
ou mesmo da indústria cultural, no período pós-guerra, permitiram uma sobrevida à expansão capitalista, já marcada por crises de superacumulação (cf. KURZ, 1993).

Os limites desta sobrevida foram dados pela chamada terceira revolução industrial ou revolução microeletrônica. Apesar do surgimento de novos setores de produção no bojo das inovações técnicas das últimas décadas, a tendência crítica que havia sido entrevista por Marx hoje se aprofunda. Estes novos setores precisam se ajustar rapidamente ao nível médio do desenvolvimento das forças produtivas, agora ultracientificizado, e não conseguem assim absorver, nas proporções necessárias, a demanda por trabalho, que contraditoriamente vai sendo encurtada. Esse processo se manifesta, do ponto de vista da população trabalhadora, como o conhecido desemprego estrutural, pauta do debate dos anos 1980 e $1990^{6}$, o qual é determinante para pensarmos na aparência de reposição da superexploração da força de trabalho. Em outras palavras, enquanto a expansão dos direitos de cidadania e a juridificação das relações de trabalho em qualquer uma das experiências particulares apresentadas foi sendo implementada, um aumento da produtividade do trabalho promovida às costas dos sujeitos foi engendrando uma concorrência gradualmente mais cruenta entre a própria população trabaIhadora, permitindo que a superexploração das forças de trabalho (mais-valia absoluta) se tornasse o modus operandi regular de setores de ponta e não apenas daqueles supostamente atrasados (ou descapitalizados).

Do ponto de vista do capital se faz necessário considerar, ainda, o aumento do trabalho improdutivo em relação ao produtivo (cf. KURZ, 2002), que se expressa na importância que o setor de serviços veio ganhando a nível mundial nas últimas décadas e, também, no alargamento e na diversificação dos campos de atividade do Estado. Exige ainda que se considere o processo contemporâneo de autonomização entre trabalho e dinheiro que leva a uma ficcionalização irreversível da reprodução do capital (cf. KURZ, 2002) ${ }^{7}$.

As experiências de mobilidade do trabalho discutidas nos itens acima podem ser agora retomadas, uma vez que o excurso teórico nos permitiu circunscreve-las

${ }^{6} \mathrm{O}$ qual ressurge atualmente sob novas formas, como precarização do trabalho e fim do trabalho assalariado, ainda que tais análises não extraiam daí as consequências mais pertinentes e determinantes para uma análise crítica do capitalismo.

${ }^{7}$ Neste particular Kurz identifica uma inversão na relação entre Estado e sociedade civil. Ao invés do Estado ser apenas um aparato tributador do dinheiro que circula na sociedade civil (no mercado), o primeiro é gradualmente levado a impulsionar uma reprodução social cada vez mais deficitária (inclusive por meio da contração de dívidas com particulares e impressão de dinheiro) movendo uma expansão de gastos e atividades improdutivas para o capital. Tais estratégias adquirem a forma da ficcionalização do capital na medida em que o capital-monetário em circulação ultrapassa de longe a produção de valor substancial (cada vez mais diminuto), postergado para se realizar no futuro, o que, todavia, nunca acontece, pelo contrário, apenas alimenta novas promessas e uma economia de bolhas financeiras (cf. KURZ, 2002). de modo não dualista (arcaico x moderno, tipicamente capitalista $\mathrm{x}$ não-tipicamente capitalista), apontando para um processo que, no conjunto, compreendemos como crise do trabalho (KURZ, 1993, 2002, 2014). Nesse sentido não apenas os expedientes contemporâneos de superexploração das forças de trabalho puderam ser reinterpretados, como os padrões territoriais de confinamento presentes em diversas escalas da reprodução social podem ser tomados como a característica contemporânea da territorialização do capital num contexto de crise de seu fundamento, o que certamente contribuirá para os debates atuais da geografia crítica. 


\section{Referências}

ALVES, V. E. L. (2000). Formação territorial sul piauiense: modernização agropecuária e resistência camponesa. Dissertação (Mestrado em Geografia Humana) - Faculdade de Filosofia, Letras e Ciências Humanas, Universidade de São Paulo, São Paulo.

(2007). Mobilização e modernização nos cerrados piauienses: formação territorial no império do agronegócio. Tese (Doutorado em Geografia Humana) - Faculdade de Filosofia, Letras e Ciências Humanas, Universidade de São Paulo, São Paulo.

ALVES, F. (2008). Trabalho e trabalhadores no corte de cana: ainda a polêmica sobre o pagamento por produção e as mortes por excesso de trabalho. In: SILVA, M. A. M.; ALVES, F.; PEREIRA; J. C. A. (orgs.). Agrocombustíveis: Solução? A vida por um fio nos canaviais. São Paulo: CCJ, p. 22-48.

AUGUSTO, A (2010). Para além da prisão-prédio: as periferias como campo de concentração a céu aberto. Cadernos Metrópole, v. 12, n, 23, p. 263-276.

BOECHAT, C. A (2009). Região do colonato: mobilização do trabalho e autonomização do capital na área de Olímpia (1857-1964). Dissertação (Mestrado em Geografia Humana) - Faculdade de Filosofia, Letras e Ciências Humanas, Universidade de São Paulo, São Paulo.

(2014). O colono que virou suco: terra, trabalho Estado e capital na modernização da citricultura paulista. Tese (Doutorado em Geografia Humana) - Faculdade de Filosofia, Letras e Ciências Humanas, Universidade de São Paulo, São Paulo.

DANTAS, I. (1987) Coronelismo e dominação. Sergipe: Programa editorial da UFS.DAMIANI, A. L. (2002) Geografia Política e novas territorialidades. In: OLIVEIRA, A. U.; PONTUSCHKA, N. N. (orgs.). Geografia em perspectiva. São Paulo: Editora Contexto, p. 17-26.

DELMONTE A. A.; RIBEIRO, C. L. (2018) Proyectos migratorios de estudiantes y profesionales que trabajan en costura: migración cualificada, interseccionalidad y descualificación. Revista Périplos, Brasília, v. 2, n. 1, p. 116-133.

FREITAS, P. T. de (2009). Imigração e experiência social: o circuito de subcontratação transnacional de força-de-trabalho boliviana para o abastecimento de oficinas de costura na cidade de São Paulo. Dissertação (Mestrado em Sociologia) - Instituto de Filosofia e Ciências Humanas, Universidade Estadual de Campinas, Campinas.

(2014) Projeto Costura: percursos sociais de trabalhadores migrantes, entre a Bolívia e a indústria da confecção das cidades de destino. Tese (Doutorado em Sociologia) - Instituto de Filosofia e Ciências Humanas, Universidade Estadual de Campinas, Campinas.

GAUDEMAR, J. P. (1977) Mobilidade do trabalho e acumulação do capital. Lisboa: Estampa.

GIAVAROTTI, D. M (2012). O Jardim Ibirapuera da imposição à crise do trabalho. Dissertação (Mestrado em Geografia Humana). Faculdade de Filosofia, Letras e Ciências Humanas, Universidade de São Paulo, São Paulo.

(2018) Eles não usam macacão: reprodução do colapso da modernização e crise do trabalho a partir da periferia de São Paulo. Tese (Doutorado em Geografia Humana). Faculdade de Filosofia, Letras e Ciências Humanas, Universidade de São Paulo, São Paulo.

GOLDBERG, A.; SILVEIRA, C. (2013). Desigualdad social, condiciones de acceso a la salud pública y procesos de atención en inmigrantes bolivianos de Buenos Aires y São Paulo: una indagación comparativa. Saúde Soc, São Paulo, v. 22, n. 2, p. 283-297.

GRAZIANO, S. J. (1982). A modernização dolorosa. Rio de Janeiro: Zahar.

HARVEY, D. (2006). Espaços de esperança. Segunda edição. São Paulo: Edições Loyola.

(2011). O Enigma do capital e as crises do capitalismo. São Paulo: Boitempo Editorial.

(2013). Os limites do capital. São Paulo: Boitempo Editorial.

KAGEYAMA, Â. (1990). O novo padrão agrícola brasileiro: do complexo rural aos complexos agroindustriais. In: DELGADO, G (org.). Agricultura e políticas públicas. Brasília: IPEA, 113-223.

KLUCK, E. G. J. (2011). O trabalho vai pro brejo: mobilização, migração e colapso da modernização. Dissertação (Mestrado em Geografia Humana) - Faculdade de Filosofia, Letras e Ciências Humanas, Universidade de São Paulo, São Paulo. 2011. 
zação do Velho Chico. Tese (Doutorado em Geografia Humana) - Faculdade de Filosofia, Letras e Ciências Humanas, Universidade de São Paulo, São Paulo.

KOWARICK, L. (1993) A espoliação urbana. Rio de Janeiro: Paz e Terra.

KURZ, R. (1993) O colapso da modernização: da derrocada do socialismo de caserna à crise da economia mundial. Segunda edição. Rio de Janeiro: Paz e Terra.

(2014) Dinheiro sem valor: linhas gerais para uma transformação da crítica da economia política. Primeira Edição. Lisboa: Antígona.

(2002) A ascensão do dinheiro aos céus: os limites estruturais da valorização do capital, o capitalismo de casino e a crise financeira global. Disponível em: < http://www.obeco-online.org/rkurz101.htm>. Acessado em: 23 jan. 2019.

(2003) Acabou-se a brincadeira: a viragem do espírito do tempo ocidental: regresso da auto-responsabilização ao autoritarismo coercivo. Disponível em: < http://obeco.planetaclix.pt/rkurz135.htm>. Acessado em: 23 jan. 2019.

LEAL, V. N. (1976) Coronelismo, enxada e voto: o município e o regime representativo no Brasil. São Paulo: Alfa-Ômega. LEITE, A. C. G. (2010) A modernização do Vale do Jequitinhonha mineiro e o processo de formação do trabalhador "bóia-fria" em suas condições regionais de mobilização do trabalho. Dissertação (Mestrado em Geografia Humana) Faculdade de Filosofia, Letras e Ciências Humanas, Universidade de São Paulo, São Paulo.

(2014) Formação e atualidade da questão regional no processo de modernização do Vale do Jequitinhonha mineiro. Boletim Campineiro de Geografia, Campinas, v. 4, n. 1, p. 60-81.

(2015) O campesinato no Vale do Jequitinhonha: da sua formação no processo de imposição do trabalho à crise da (sua) reprodução capitalista. Tese (Doutorado em Geografia Humana) - Faculdade de Filosofia, Letras e Ciências Humanas, Universidade de São Paulo, São Paulo.

; GIAVAROTTI, D. M. (2018) Entrevista com Moishe Postone: Revista Margem Esquerda, São Paulo, n. 31, p. 11-

28.

LENIN, V. I. (2010) O Imperialismo, fase superior do capitalismo. Quarta edição. São Paulo: Centauro Editora.

LUXEMBURGO, R. (1985) A acumulação do capital. São Paulo: Nova Cultural.

MARINI, R. M. (2005) Dialética da Dependência. In: TRASPADINI, R.; STÉDILE, J. P. (orgs.). Ruy Mauro Marini: Vida e Obra. São Paulo: Editora Expressão Popular, p. 131-172.

MARTINS, J. S. (1981) Os camponeses e a política no Brasil: as lutas sociais no campo e seu lugar no processo político. Petrópolis: Vozes.

MARTINS, J. S. (2004) O cativeiro da terra. São Paulo: Hucitec.

MARX, K. (1985a) O capital: crítica da economia política. São Paulo: Abril Cultural. Livro Primeiro, Volume I. Tomo 1.

Tomo 2.

(1985b) 0 capital: crítica da economia política. Edição. São Paulo: Nova Cultural. Livro Primeiro. Volume I.

(1986) O capital: crítica da economia política. Edição. São Paulo: Nova Cultural. Livro Terceiro. Volume IV. Tomo

2.

(1988) O capital: crítica da economia política. Edição. São Paulo: Nova Cultural. Livro Terceiro. Volume IV. Tomo

1.

MIRANDA, B. (2017) "Uno ya sabe a lo que viene": la movilidad laboral de migrantes andino-bolivianos entre talleres de costura de São Paulo explicada a la luz de la producción del consentimiento. Revista Interdisciplinar da Mobilidade Humana, Brasília, v. 25, n. 49, p. 197-213.

MONTERO, J. (2014) Discursos de moda: ¿Cómo justificar la explotación de inmigrantes en talleres de costura? Trabajo y sociedad, Santiago del Estero, n. 23, v. 17, p. 107-125.

NOVAIS, F. (2005) Portugal e Brasil na crise do antigo sistema colonial (1777-1808). São Paulo: Hucitec.

OLIVEIRA, Ariovaldo Umbelino de. (1999) A Geografia Agrária $\mathrm{e}$ as transformações territoriais recentes no campo brasileiro. In: CARLOS, A. F. A. (org.). Novos caminhos da Geografia. São Paulo: Editora Contexto, p. 63-110.

OLIVEIRA, F. (1987) Elegia para uma re(li)gião: sudene, planejamento e conflito de classes. Rio de Janeiro: Paz e Terra. . (1998) Os direitos do antivalor: a economia política da hegemonia imperfeita. Petrópolis: Vozes. 
(2003) Crítica à razão dualista e 0 ornitorrinco. São Paulo: Boitempo.

(2006) O vício da virtude: autoconstrução e acumulação capitalista no Brasil. Novos Estudos CEBRAP, São Paulo, n. 74, v. 1, p. 67-85.

; MAZZUCCHELLI, F. (1977) Padrões de acumulação, oligopólios e Estado no Brasil: 1950-1976. In: MARTINS, C. E. (org.). Estado e capitalismo no Brasil. São Paulo: Hucitec/CEBRAP, p. 111-140.

POSTONE, M. (2014) Tempo, trabalho e dominação social: uma reinterpretação da teoria crítica de Marx. Primeira edição. São Paulo: Boitempo Editorial.

PÓVOA NETO, H. (1998) No caminho das pedras: itinerários na formação da mobilidade garimpeira no Brasil. Tese (Doutorado em Geografia Humana) - Faculdade de Filosofia, Letras e Ciências Humanas, Universidade de São Paulo, São Paulo.

PRADO JR., C. (1979). Formação do Brasil contemporâneo: colônia. São Paulo: Brasiliense.

RAFFESTIN, C. (1993) Por uma geografia do poder. São Paulo: Ática.

RAMOS, P. (2007) 0 uso de mão-de-obra na lavoura canavieira: da legislação (agrária) do Estado Novo ao trabalho super-explorado na atualidade. Anais II Seminário de História do Açúcar: Trabalho População e Cotidiano, São Paulo. Editora do Museu Paulista da USP.

REDE SOCIAL DE JUSTIÇA E DIREITOS HUMANOS. (2009) Direitos Humanos no Brasil 2009. São Paulo.

RIBEIRO, C. L. (2018) Gênero e mobilidade do trabalho: bolivianas trabalhadoras na indústria de confecção de São Paulo. Dissertação (Mestrado em Geografia Humana) - Faculdade de Filosofia, Letras e Ciências Humanas. Universidade de São Paulo, São Paulo.

SILVA, M. A. M. (1988) A migração de mulheres do Vale do Jequitinhonha para São Paulo: de camponesas a proletárias. Travessia, a revista do migrante, São Paulo, v. 1, n. 1, p. 16-20.

(1999) Errantes do fim do século. São Paulo: Editora UNESP.

SILVA, M. A. M.; BUENO, J. D.; VERÇOZA, L. V. (2013) 0 trabalho à flor da pele: formas contemporâneas do estranhamento nos canaviais. Cadernos Ceru, São Paulo, v. 24, n. 1, p. 13-38.

SILVA, A. R. C. (2013) Imigrantes afro-islâmicos na indústria avícola halal brasileira. Dissertação (Mestrado em Geografia Humana) - Faculdade de Filosofia, Letras e Ciências Humanas, Universidade de São Paulo, São Paulo.

(2018) Imigrantes africanos solicitantes de refúgio: Cooperação para o desenvolvimento e humanitarismo no Atlântico Sul. Tese (Doutorado em Geografia Humana) - Faculdade de Filosofia, Letras e Ciências Humanas, Universidade de São Paulo, São Paulo.

SILVA, C. F. (2008) Trabalho informal e redes de subcontratação: Dinâmicas urbanas da indústria de confecções em São Paulo. Dissertação (Mestrado em Sociologia) - Faculdade de Filosofia, Letras e Ciências Humanas, Universidade de São Paulo, São Paulo.

SILVA, S. A. (1997) Costurando sonhos - trajetória de um grupo de bolivianos em São Paulo. São Paulo: Paulinas.

SEABRA, O. C. de L. (2003) Urbanização e Fragmentação - Cotidiano e vida de bairro na metamorfose da cidade em metrópole, a partir das transformações do bairro do Limão. (Livre Docência em Geografia Humana) - Faculdade de Filosofia, Letras e Ciências Humanas, Universidade de São Paulo, São Paulo.

THOMAZ JR., A. (2002) Por trás dos canaviais: os nós da cana. Edição. São Paulo: Annablume/FAPESP.

TOLEDO, C. de A. (2001) A mobilização do trabalho nas Lavras Baianas. Dissertação (Mestrado em Geografia Humana). Faculdade de Filosofia, Letras e Ciências Humanas, Universidade de São Paulo, São Paulo, 2001.

(2008) A região das lavras Baianas. Tese (Doutorado em Geografia Humana). Faculdade de Filosofia, Letras e Ciências Humanas, Universidade de São Paulo, São Paulo.

VAINER, C. B. (1984) Trabalho, espaço e Estado: questionando a questão migratória. Cadernos PUR, Rio de Janeiro, p. $1-51$. 